- important exception - as well as the contents of Hinton's trunk, are also enriched with chromium. This appears to have been a result of the staining process.

Before staining, Hinton would have used chromic acid as an ingredient in a recipe to turn the apatite (the mineral component of bone) to gypsum. This process would have etched the bone surface, making it easier for the manganese and iron oxides to penetrate the specimens. But traces of chromium would remain.

The one exception was the orang-utan jaw. This could not be etched because it contained two teeth, and acid-etching of the teeth would have been a clear sign of a forger at work. Hinton was therefore careful not to treat these in the same way. The teeth were lightly stained so as not to risk etching, and an isolated canine tooth was painted further with paint (possibly burnt umber) rich in manganese and iron.

Gardiner and Currant's suspicions about Hinton's difficulties with teeth received support in 1991 after Gardiner contacted Robert J. G. Savage, then professor of geology at the University of Bristol, telling him of Currant's discovery of the Hinton trunk. Savage had been the executor of Hinton's estate - a considerable task, given that Hinton was a lifelong hoarder.

Savage sent Gardiner some glass tubes from Hinton's hoard. These contained eight human teeth that had been stained in various ways. The teeth, together with the con- tents of the trunk, reveal a forger testing out his methods. The staining recipe of iron, manganese and chromium seems to have been Hinton's own, based on his knowledge of post-depositional processes affecting fossils in gravel.

Why the Piltdown gravels? Hinton was an expert on the geology of the Weald area of Sussex, in which Piltdown is located: Gardiner and Currant believe Hinton chose the Piltdown gravels precisely because they were entirely unfossiliferous, leaving Hinton a clear field Hinton (centre) at work in the Natural History Museum. to execute the fraud. Dawson and, through him, Smith Woodward, was led to the scene - and the rest is history.

Hinton knew Dawson was an incompetent geologist and would serve as the dupe; Dawson had already unknowingly traded a stone implement, stained to look old by Hinton, with Harry Morris, an expert on stone tools. This later turned up in Morris's collection labelled that it had been stained by Dawson with intent to defraud. Gardiner argues that Dawson is unlikely to have traded a flint he had faked with an expert such as Morris if he had he done it himself.

The real victim seems to have been Smith Woodward, and the motive an argument about money. In 1910, Hinton wrote to Smith Woodward asking for vacation

\section{Basic research wins out in UK spending}

London. Policy changes introduced by the British government over the past ten years have resulted in a major shift in the balance of public spending on research and development (R\&D), according to figures released by the government this week as part of its annual Forward Look.

In particular, basic research has increased its total share of such spending from 19.1 per cent in 1985-86 to 33.3 per cent in 1994-95. In contrast, government spending on 'experimental development' has fallen from 44.2 to 28.9 per cent of its total $R \& D$ expenditure, in line with its commitment to pass responsibility for such investment to the private sector.

Largely as a result of an accelerated shift in this latter direction, overall spending by the British government on civilian research and development, after a spurt at the beginning of the decade, has slowed down again. The figures published this week show that total expenditure on civilian $R \& D$ increased last year by only 1.4 per cent in cash terms - to a total of $£ 3.17$ billion (US $\$ 4.79$ million) - compared to a 4.4. per cent increase the previous year.
A major drop in spending on military research in particular has meant that the government's total R\&D budget fell in cash terms for the first time for more than a decade. But spending on the science and engineering base - including the seven research councils - grew by 4.1 per cent, slightly higher than inflation. Basic research has increased its share of the civilian R\&D budget from 35.1 per cent in $1985-86$ to 54.9 per cent last year.

In terms of public spending on R\&D by socio-economic objectives, the proportion spent on health has increased from 4.5 to 7.6 per cent between 1986-87 and 1994-95, and on environmental protection from 1.1 to 2.3 per cent. In contrast, spending on new energy sources has seen its share of the total fall from 4.4 to 1.1 per cent.

Sir Robert May, head of the Office of Science and Technology and the government's chief scientific adviser, says that a special effort has been made to make the report, which is intended to provide the government with an annual transdepartmental 'snapshot' of science spending, more readable than in the previous two years.

\section{IMAGE UNAVAILABLE FOR COPYRIGHT REASONS}

employment cataloguing rodent remains at the museum. Woodward agreed, provided the payment of $£ 130$ was made after completion of the work, as was customary.

Hinton responded with a letter requesting that the sum be paid as a weekly wage, and detailing elaborate and costly plans for a catalogue. Woodward's reply, if any, does not survive, but as a senior figure (and experienced cataloguer) he is unlikely to have been impressed by the presumption of a junior colleague.

Whatever the outcome of the dispute, Hinton spent most of his subsequent career in the zoology department of the museum, away from Woodward's palaeontology department - even though much of Hinton's work concerned fossils.

Although the evidence of Hinton's responsibility appears strong, some doubts will inevitably remain among those who have studied the case closely. "It's a very convincing link between Piltdown and Hinton," says Chris Stringer, a palaeoanthropologist at the Natural History Museum. "But I still have my suspicions that Dawson was involved."

But Gardiner feels that the evidence for Hinton having been the sole hoaxer is now conclusive. He points out, for example, that Hinton was well-known for his elaborate practical jokes. The Piltdown fraud would have been an ideal way to get back at the pompous, stuffy keeper of palaeontology. Such suspicions are strengthened by the text of a letter Hinton wrote in 1954 to the evolutionary biologist Gavin de Beer - then the director of the British Museum (Natural History), now the Natural History Museum - after the fraud had been exposed.

"The temptation to invent such a discovery of an ape-like man associated with late Pliocene mammals in a Wealden gravel might well have proved irresistible to some unbalanced member of old Ben Harrison's circle at Ightham," wrote Hinton, a reference to his circle of Sussex-based geologist colleagues. "He [Harrison] and his friends [of whom Hinton was one] were always talking of the possibility of finding a late Pliocene deposit in the Weald." Given what we now know, this reads as almost a signed confession.

Henry Gee 